\title{
PILOCYTIC ASTROCYTOMA WITH SPECIFIC GENE SIGNATURE
}

Researchers at Universite de la Mediterranee, and other centers in Marseille, France, using the microarray technique to compare the transcriptional profiles of five optic pathway, hypothalamo-chiasmatic and six cerebellar pilocytic astrocytomas, found that these 2 tumors are genetically distinct and topography-dependent entities. NOTCH2, a gene expressed in radial glia and involved in gliomagenesis, was upregulated in hypothalamo-chiasmatic pilocytic astrocytomas. A morphological study of the chiasma identified, in the floor of the third ventricle, a unique population of cells resembling radial glial cells from which the tumor originates. (Tchoghandjian A, Fernandez C, Colin C, et al. Pilocytic astrocytoma of the optic pathway: a tumour deriving from radial glia cells with a specific gene signature. Brain June 2009;132:1523-1535). (Respond: Prof D Figarella-Branger, Universite de la Mediterranee, 27 bd Jean Moulin 13285 Marseille cedex 05, France. E-mail: dominique.figarella-branger@univmed.fr).

COMMENT. Pilocytic astrocytomas are grade I gliomas of childhood that share features of astroglia and oligodendroglia, and affect the cerebellum or the optic pathway, especially the hypothalamo-chiasmatic region. The 2 tumors differ in their localization but also in prognosis. The cerebellar pilocytic astrocytoma has a benign course whereas the optic pathway tumor has a poor prognosis. The present study demonstrating distinct differences and the molecular basis responsible for the aggressive behavior of the optic pathway tumor may allow the development of new molecular targeted therapies.

\section{CEREBELLAR ATAXIAS}

\section{ATAXIA-TELANGIECTASIA WITH HYPER-IgM SYNDROME}

A group of eight children with ataxia-tengiectasia (A-T) who presented with serum Ig levels suggestive of hyper-IgM syndrome (HIGM) are reported from the Department of Paediatrics, Reinier de Graaf Gasthuis, Delft, and other centers in the Netherlands, Iceland, and Belgium. All patients ultimately showed clinical features of A-T (ataxia, telangiectasia, recurrent respiratory tract infection), and all had raised serum a-fetoprotein levels; in 7 the diagnosis of A-T was confirmed by DNA analysis. (Noordzij JG, Wulffraat NM, Haraldsson A, et al. Ataxia-telangiectasia patients presenting with hyper-IgM syndrome. Arch Dis Child June 2009;94:448-449). (Respond: Dr JG Noordzij, Department of Paediatrics, Reiner de Graaf Gasthuis, PO Box 5011, 2600 GA Delft, The Netherlands. E-mail: j.noordzij@,rdgg.nl).

COMMENT. Hyper-IgM syndrome is a primary immunodeficiency disease that presents with recurrent infections, decreased serum immunoglobulin IgG and IgA and normal or raised IgM levels. Ataxia-telangiectasia also presents with recurrent infections, and at an early age the ataxia and telangiectasia may be absent. Immunodeficiency in A-T is associated with decreased serum IgG and/or IgA levels, and 10\% of cases have normal or raised IgM levels. In the absence of typical clinical signs of A-T, the diagnosis may be confused with hyper-IgM syndrome. Elevated a-fetoprotein and low T lymphocytes distinguish A-T cases. 